\title{
Prognostic impact of a new score using neutrophil-to-lymphocyte ratios in the serum and malignant pleural effusion in lung cancer patients
}

Yong Seok Lee ${ }^{1}$, Hae-Seong Nam² ${ }^{*}$, Jun Hyeok Lim², Jung Soo Kim², Yeonsook Moon³, Jae Hwa Cho², Jeong-Seon Ryu' ${ }^{2}$ Seung Min Kwak² and Hong Lyeol Lee ${ }^{2}$

\begin{abstract}
s
Backgrounds: Various studies have reported that the neutrophil-to-lymphocyte ratio in the serum (sNLR) may serve as a cost-effective and useful prognostic factor in patients with various cancer types. However, no study has reported the prognostic impact of the NLR in malignant pleural effusion (MPE). To address this gap, we investigated the clinical impact of NLR as a prognostic factor in MPE (mNLR) and a new scoring system that use NLRs in the serum and MPE (smNLR score) in lung cancer patients.

Methods: We retrospectively reviewed all of the patients who were diagnosed with lung cancer and who presented with pleural effusion. To maintain the quality of the study, only patients with malignant cells in the pleural fluid or tissue were included. The patients were classified into three smNLR score groups, and clinical variables were investigated for their correlation with survival.

Results: In all, 158 patients were classified into three smNLR score groups as follows: 84 (53.2\%) had a score of 0, 58 (36.7\%) had a score of 1 , and $16(10.1 \%)$ had a score of 2 . In a univariate analysis, high sNLR, mNLR, and increments of the smNLR score were associated with shorter overall survival $(p<0.001, p=0.004$, and $p<0.001$, respectively); moreover, age, Eastern Cooperative Oncology Group performance status (ECOG PS), histology, M stage, hemoglobin level, albumin level, and calcium level were significant prognostic factors. A multivariable analysis confirmed that ECOG PS $(p<0.001)$, histology $(p=0.001)$, and smNLR score $(p<0.012)$ were independent predictors of overall survival.
\end{abstract}

Conclusions: The new smNLR score is a useful and cost-effective prognostic factor in lung cancer patients with MPE. Although further studies are required to generalize our results, this information will benefit clinicians and patients in determining the most appropriate therapy for patients with MPE.

Keywords: Lung cancer, Malignant pleural effusion, Neutrophil-to-lymphocyte ratio, Prognostic factor, Serum

\footnotetext{
* Correspondence: hsnam@inha.ac.kr

${ }^{2}$ Division of Pulmonology, Department of Internal Medicine, Inha University Hospital, Inha University School of Medicine, 27, Inhang-ro, Jung-gu, Incheon 22332, South Korea

Full list of author information is available at the end of the article
} 


\section{Background}

Malignant pleural effusions (MPEs), which are diagnosed based on the identification of malignant cells in the pleural fluid or on pleural biopsy, represent an advanced malignant disease that is associated with high morbidity and mortality; these characteristics preclude the possibility of a curative treatment approach. Despite major advances in cancer treatment over the past two decades, the median survival time (MST) following a diagnosis of MPE depends on the origin of the primary tumor as well as its histological type and stage, and usually ranges from 4 to 12 months. Lung cancer patients with MPE have the shortest survival times. For this reason, the revised staging system for lung cancer upstaged the presence of MPE from T4 to M1a [1-5].

These patients with advanced lung cancer experienced an improvement in their quality of life and received less aggressive care at the end of their lives with early palliative care than with the current standard of care [6]. In addition, palliative care is favorable in terms of medical cost savings. These results suggest an urgent need to develop more useful and cost-effective clinical prognostic factors that may help to select the most appropriate care and to minimize inconvenience for the remainder of the patients' lives. However, many studies have reported various molecular biomarkers that may predict the prognoses of cancer patients, but technical factors and excessive costs still preclude their clinical use [7].

Recently, a meta-analysis comprising 100 studies reported that an elevated neutrophil-to-lymphocyte ratio in the serum (sNLR), which is one of several systemic inflammatory markers, is associated with an adverse overall survival (OS) many types of solid tumors, and thus the sNLR may serve as a useful and cost-effective prognostic factor [8]. However, no study on the NLR of MPE (mNLR) has been reported thus far. Only one study showed that high neutrophil levels in MPE were significantly associated with adverse OS of patients with MPE [9]. These data suggest that the mNLR, like the sNLR, may serve as a new prognostic factor in patients with MPE.

Accordingly, we questioned whether the mNLR has a prognostic impact in patients with MPE. To address this question, we reviewed different cell counts of MPE in lung cancer patients who presented with pleural effusion and investigated the prognostic impact of the mNLR. Furthermore, we investigated the clinical impact of a new scoring system that incorporates the NLRs in the serum and MPE (smNLR score).

\section{Methods}

\section{Study population}

We retrospectively reviewed all patients diagnosed with lung cancer who presented with pleural effusion between
2002 and 2010 at Inha University Hospital. To maintain the quality of the study, only patients with malignant cells confirmed in the pleural fluid or on pleural biopsy were included in the study. To identify malignant cells in effusion fluid and/or pleural biopsy tissue, a conventional cytology examination and/or histological analyses were performed independently. With respect to the conventional cytologic examination, $5 \sim 10 \mathrm{ml}$ of effusion fluid obtained by diagnostic thoracentesis was centrifuged at $2500 \mathrm{rpm}$ for $10 \mathrm{~min}$, and a minimum of two thin smears were prepared from the sediment. One smear was air-dried and stained with Leishman-Giemsa stain, and the other smear was immediately fixed in $95 \%$ alcohol and stained with Papanicolaou stain according to the hospital pathology laboratory's standard protocol. With respect to the histological analyses, tissue specimens obtained during pleural biopsy were processed after formalin fixation; sections were then stained with hematoxylin-eosin dye. The stages of all patients were defined according to the seventh edition of the TNM classification system [4]. The study protocol was approved by the Institutional Review Board of Inha University Hospital. Informed consent was waived because of the retrospective nature of the study.

\section{Data collection}

Baseline prognostic clinical and laboratory variables were collected retrospectively from the electronic medical record system. Patient-related variables included age, gender, smoking status, Eastern Cooperative Oncology Group performance status (ECOG PS), and the serum levels of hemoglobin, albumin, lactate dehydrogenase (LDH), and calcium at diagnosis. The tumor-related variables consisted of histology and stage. Finally, the treatment variables were classified into two subgroups, as follows: active treatments, including systemic chemotherapy and/ or radiation therapy to the lung, and supportive treatments, including supportive care, refusal of treatment, and radiation therapy to metastatic sites for symptomatic palliation.

The NLRs were obtained by dividing the absolute number of neutrophils by the number of lymphocytes in the complete blood count of the serum at diagnosis and in the total cell count of MPE obtained during diagnostic thoracentesis.

\section{The new score using NLRs of the serum and MPE (smNLR score)}

The optimal cutoff values for the sNLR and the mNLR were determined using maximally selected rank statistics [10, 11]. Maximally selected rank statistics were calculated using $\mathrm{R}$ software, version 3.03 (The R Foundation for Statistical Computing, Vienna, Austria; http://www.r-project.org) and the 'maxstat' 
package. According to the cutoff values for the sNLR and the mNLR, we defined the smNLR score as follows: patients in whom both the $\operatorname{sNLR}(\geq 3.85)$ and the mNLR $(\geq 1.36)$ were elevated were assigned a score of 2 . Patients in whom only one of the two NLR values was elevated were assigned a score of 1 . Patients in whom neither the sNLR nor mNLR valuess was elevated were assigned a score of 0 .

\section{Statistical analysis}

OS was measured as an outcome and was estimated from the time of diagnosis until death as a result any cause. Only two patients died of causes other than lung cancer. The distribution of variables according to the smNLR score was assessed by $x^{2}$ tests. Survival analyses were performed using the Kaplan-Meier method and log-rank test. Potential predictors of survival were entered into univariate Kaplan-Meier models and compared using the logrank test. Factors with a prognostic association in the univariate analysis were entered into a multivariate Cox regression model (forward sequential method) to determine their independent effects. The results of the Cox regression modeling are presented as hazard ratios and associated 95\% confidence intervals. Variables with $p$-values less than 0.05 were considered statistically significant. All analyses were performed using the IBM SPSS statistical software package version 19.0 (SPSS, Chicago, IL, USA).

\section{Results}

\section{Patient characteristics}

In all, 158 patients underwent diagnostic thoracentesis. Eighty-one of these patients also underwent parietal pleural biopsy. A diagnosis of MPE was confirmed by both cytology and biopsy in 62 patients, by cytology alone in 84 patients, and by biopsy alone in 12 patients. No causes of infection, such as bacteria, tuberculosis, or viruses, were identified in the blood, sputum, or MPE of any of the cases. The baseline characteristics of the study population are summarized in Table 1 . The median age of the patients was 68 years (range: 32-89), and 81 patients were male $(51.3 \%)$. The majority of patients were former or current smokers (53.8\%), had an ECOG PS of $0-1$ (59.5\%) and exhibited an adenocarcinoma histology (85.4\%). At the time of diagnosis, $51.9 \%$ of patients had distant metastases in other organs outside the lung (M1b). The percentages of patients who received supportive and active treatments were 46.8 and 53.2\%, respectively. Seventy-six patients in the active treatment group received chemotherapy; out of these, 70 patients received platinum-based doublet chemotherapy and 6 patients received gemcitabine monotherapy; the other 8 patients received radiation therapy to the lung. All of the patients died. Survival data was collected from the electronic medical record system and the Korean Ministry of Security and Public Administration.
Clinical factors associated with the new smNLR score All patients were classified into one of three smNLR score groups as follows: 84 (53.2\%) had a score of 0,58 (36.7\%) had a score of 1 , and $16(10.1 \%)$ had a score of 2 . The clinical and laboratory factors associated with the three smNLR score groups are shown in Table 1. The mean \pm standard deviation of the sNLR and the mNLR were $4.91 \pm 3.99$ (range: $1.21-24.43$ ) and $0.64 \pm 1.74$ (range: 0.00-17.20), respectively. Age, gender, smoking status, treatment, hemoglobin, $\mathrm{LDH}$, and calcium were not significantly different among the three groups. However, besides the $\operatorname{sNLR}(p<0.001)$ and the mNLR $(p<0.001)$, ECOG PS $(p=0.001)$, histologic type $(p=0.023), \mathrm{M}$ stage $(p=0.002)$, and the level of albumin $(p<0.001)$ exhibited significant differences among the three groups.

\section{Types of NLRs and overall survival}

The MST of all patients was 7.7 months (95\% confidence interval: $5.3 \sim 10.1$ ). The results of the univariate analyses of individual baseline variables are listed in Table 2. The following variables were associated with shorter OS: age $\geq 65(p<0.001)$, ECOG PS $2-4(p<0.001)$, nonadenocarcinoma histologic type $(p<0.001)$, M1b stage $(p=0.002)$, palliative treatment $(p=0.007)$, anemia $(p=0.004)$, hypoalbuminemia $(p<0.001)$, and hypercalcemia $(p<0.001)$. All types of NLRs (sNLR, mNLR and smNLR score) were also significant prognostic factors in the univariate analysis, as follows: high SNLR and mNLR were associated with a shorter OS ( $\operatorname{NLR}<3.85$ vs $\geq 3.85$, MST 12.6 vs 3.6 months, respectively, $p<0.001$, Fig. 1a; and $\mathrm{mNLR}<1.36$ vs $\geq 1.36$, MST 8.3 vs 2.4 months, respectively, $p=0.004$, Fig. 1b). An increment in the smNLR score was also associated with a shorter OS (smNLR score 0 vs 1 vs 2 , MST 12.6 vs 4.4 vs 1.6 months, respectively, $p<0.001$, Fig. 1c).

Individual variables that were analyzed in the univariate analyses were entered into the multivariate Cox model, irrespective of their significance. A multivariate analysis revealed the following prognostic variables to be independent predictors of shorter OS (Table 2): ECOG PS 2-4 $(p<0.001)$, non-adenocarcinoma histologic type $(p=0.001)$, and increments in the smNLR score $(p<0.012)$. On the contrary, a multivariate analysis apart from the smNLR score showed that age $>65$ $(p=0.046)$, ECOG PS $2-4(p<0.001)$, non-adenocarcinoma histologic type $(p=0.02)$, and an sNLR $\geq 3.85$ $(p=0.007)$ were independent predictors of shorter OS (Additional file 1: Table S1).

\section{Discussion}

In this study, we found that the sNLR, mNLR and smNLR scores are significant prognostic factors for adverse OS in lung cancer patients with MPE. Furthermore, the new 
Table 1 Baseline characteristics according to the new score, which uses the neutrophil-to-lymphocyte ratios in serum and malignant pleural effusion (smNLR score) in lung cancer patients

\begin{tabular}{|c|c|c|c|c|c|}
\hline \multirow[t]{2}{*}{ Variable } & \multirow{2}{*}{$\begin{array}{l}\text { Total } \\
n=158\end{array}$} & \multicolumn{3}{|c|}{ smNLR score } & \multirow[t]{2}{*}{$P$ value } \\
\hline & & $0(n=84)$ & $1(n=58)$ & $2(n=16)$ & \\
\hline Age, years & & & & & 0.246 \\
\hline $\begin{array}{l}<65 \\
\geq 65\end{array}$ & $\begin{array}{l}60(38.0) \\
98(62.0)\end{array}$ & $\begin{array}{l}37(44.0) \\
47(56.0)\end{array}$ & $\begin{array}{l}18(31.0) \\
40(69.0)\end{array}$ & $\begin{array}{l}5(31.3) \\
11(68.7)\end{array}$ & \\
\hline Sex & & & & & 0.167 \\
\hline $\begin{array}{l}\text { Male } \\
\text { Female }\end{array}$ & $\begin{array}{l}81(51.3) \\
77(48.7)\end{array}$ & $\begin{array}{l}40(47.6) \\
44(52.4)\end{array}$ & $\begin{array}{l}35(60.3) \\
23(39.7)\end{array}$ & $\begin{array}{l}6(37.5) \\
10(62.5)\end{array}$ & \\
\hline Smoking habit & & & & & 0.391 \\
\hline $\begin{array}{l}\text { Current + Former } \\
\text { Never }\end{array}$ & $\begin{array}{l}85(53.8) \\
73(46.2)\end{array}$ & $\begin{array}{l}43(51.2) \\
41(48.8)\end{array}$ & $\begin{array}{l}35(60.3) \\
23(39.7)\end{array}$ & $\begin{array}{l}7(43.8) \\
9(56.2)\end{array}$ & \\
\hline ECOG PS & & & & & 0.001 \\
\hline $\begin{array}{l}0-1 \\
2-4\end{array}$ & $\begin{array}{l}94(59.5) \\
64(40.5)\end{array}$ & $\begin{array}{l}61(72.6) \\
23(27.4)\end{array}$ & $\begin{array}{l}28(48.3) \\
30(51.7)\end{array}$ & $\begin{array}{l}5(31.3) \\
11(68.7)\end{array}$ & \\
\hline Histology & & & & & 0.023 \\
\hline $\begin{array}{l}\text { ADC } \\
\text { SQC } \\
\text { Others } \\
\text { SCC }\end{array}$ & $\begin{array}{l}135(85.4) \\
9(5.7) \\
5(3.2) \\
9(5.7)\end{array}$ & $\begin{array}{l}77(91.6) \\
4(4.8) \\
0(0.0) \\
3(3.6)\end{array}$ & $\begin{array}{l}48(82.8)) \\
2(3.4) \\
4(6.9) \\
4(6.9)\end{array}$ & $\begin{array}{l}10(62.5) \\
3(18.8) \\
1(6.2) \\
2(12.5)\end{array}$ & \\
\hline M Stage & & & & & 0.002 \\
\hline $\begin{array}{l}\text { M1a } \\
\text { M1b }\end{array}$ & $\begin{array}{l}76(48.1) \\
82(51.9)\end{array}$ & $\begin{array}{l}51(60.7) \\
33(39.3)\end{array}$ & $\begin{array}{l}21(36.2) \\
37(63.8)\end{array}$ & $\begin{array}{l}4(25.0) \\
12(75.0)\end{array}$ & \\
\hline Treatment & & & & & 0.056 \\
\hline $\begin{array}{l}\text { Supportive } \\
\text { Active }\end{array}$ & $\begin{array}{l}74(46.8) \\
84(53.2)\end{array}$ & $\begin{array}{l}32(38.1) \\
52(61.9)\end{array}$ & $\begin{array}{l}32(55.2) \\
26(44.8)\end{array}$ & $\begin{array}{l}10(62.5) \\
6(37.5)\end{array}$ & \\
\hline Hemoglobin, $\mathrm{g} / \mathrm{dL}^{\mathrm{a}}$ & & & & & 0.170 \\
\hline $\begin{array}{l}<12 \\
\geq 12\end{array}$ & $\begin{array}{l}59(37.3) \\
99(62.7)\end{array}$ & $\begin{array}{l}27(32.1) \\
57(67.9)\end{array}$ & $\begin{array}{l}23(39.7) \\
35(60.3)\end{array}$ & $\begin{array}{l}9(56.2) \\
7(43.8)\end{array}$ & \\
\hline Albumin, $\mathrm{g} / \mathrm{dL}^{\mathrm{a}}$ & & & & & $<0.001$ \\
\hline $\begin{array}{l}<3.1 \\
\geq 3.1\end{array}$ & $\begin{array}{l}30(19.0) \\
128(81.0)\end{array}$ & $\begin{array}{l}7(8.3) \\
77(91.7)\end{array}$ & $\begin{array}{l}15(25.9) \\
43(74.1)\end{array}$ & $\begin{array}{l}8(50.0) \\
8(50.0)\end{array}$ & \\
\hline $\mathrm{LDH}, \mathrm{IU} / \mathrm{L}^{\mathrm{a}}$ & & & & & 0.261 \\
\hline $\begin{array}{l}\leq 211 \\
>211\end{array}$ & $\begin{array}{l}76(48.1) \\
82(51.9)\end{array}$ & $\begin{array}{l}45(53.6) \\
39(46.4)\end{array}$ & $\begin{array}{l}23(39.7) \\
35(60.3)\end{array}$ & $\begin{array}{l}8(50.0) \\
8(50.0)\end{array}$ & \\
\hline Calcium, mg/dL ${ }^{a}$ & & & & & 0.140 \\
\hline $\begin{array}{l}\leq 10.8 \\
>10.8\end{array}$ & $\begin{array}{l}156(98.7) \\
2(1.3)\end{array}$ & $\begin{array}{l}83(98.8) \\
1(1.2)\end{array}$ & $\begin{array}{l}58(100) \\
0(0.0)\end{array}$ & $\begin{array}{l}15(93.7) \\
1(6.3)\end{array}$ & \\
\hline sNLR & & & & & $<0.001$ \\
\hline $\begin{array}{l}<3.85 \\
\geq 3.85\end{array}$ & $\begin{array}{l}87(55.1) \\
71(44.9)\end{array}$ & $\begin{array}{l}84(100) \\
0(0.0)\end{array}$ & $\begin{array}{l}3(5.2) \\
55(94.8)\end{array}$ & $\begin{array}{l}0(0.0) \\
16(100)\end{array}$ & \\
\hline $\mathrm{mNLR}$ & & & & & $<0.001$ \\
\hline $\begin{array}{l}<1.36 \\
\geq 1.36\end{array}$ & $\begin{array}{l}139(88.0) \\
19(12.0)\end{array}$ & $\begin{array}{l}84(100) \\
0(0.0)\end{array}$ & $\begin{array}{l}55(94.8) \\
3(5.2)\end{array}$ & $\begin{array}{l}0(0.0) \\
16(100)\end{array}$ & \\
\hline
\end{tabular}

Data in parentheses are percentages

Abbreviations: ECOG PS Eastern Cooperative Oncology Group performance status, ADC adenocarcinoma, SQC squamous cell carcinoma, SCC small cell carcinoma, $L D H$ lactate dehydrogenase, $s N L R$ neutrophil-to-lymphocyte ratio of serum, $m N L R$ neutrophil-to-lymphocyte ratio of malignant pleural effusion

${ }^{\mathrm{a}}$ Dichotomized by cutoff of normal value

smNLR score was found to be a more significant independent prognostic factor than the sNLR alone, which has been reported as a prognostic factor in patients with various types of cancer $[8,12-19]$. The smNLR score is readily calculated, inexpensive, and universally available in clinical settings from the different cell counts in the serum and MPE. Therefore, the smNLR score could potentially be an attractive and ideal prognostic factor that predicts 
Table 2 Univariate and multivariate analyses of the factors that are predictive of overall survival in all patients $(n=158)$

\begin{tabular}{|c|c|c|c|c|c|c|}
\hline \multirow[t]{2}{*}{ Variable } & \multicolumn{3}{|c|}{ Univariate analysis } & \multicolumn{3}{|c|}{ Multivariate analysis } \\
\hline & MST, mo & $95 \% \mathrm{Cl}$ & $P$ value & $\mathrm{HR}$ & $95 \% \mathrm{Cl}$ & $P$ value \\
\hline Age, years & & & $<0.001$ & & & \\
\hline $\begin{array}{l}<65 \\
\geq 65\end{array}$ & $\begin{array}{l}13.6 \\
4.3\end{array}$ & $\begin{array}{l}11.1-16.2 \\
2.7-5.9\end{array}$ & & & & \\
\hline Sex & & & 0.103 & & & \\
\hline $\begin{array}{l}\text { Male } \\
\text { Female }\end{array}$ & $\begin{array}{l}5.0 \\
9.5\end{array}$ & $\begin{array}{l}2.8-7.3 \\
6.5-12.5\end{array}$ & & & & \\
\hline Smoking habit & & & 0.052 & & & \\
\hline $\begin{array}{l}\text { Current + Former } \\
\text { Never }\end{array}$ & $\begin{array}{l}4.5 \\
9.7\end{array}$ & $\begin{array}{l}2.1-6.9 \\
6.8-12.6\end{array}$ & & & & \\
\hline ECOG PS & & & $<0.001$ & & & $<0.001$ \\
\hline $\begin{array}{l}0-1 \\
2-4\end{array}$ & $\begin{array}{l}13.6 \\
2.4\end{array}$ & $\begin{array}{l}11.8-15.4 \\
1.5-3.3\end{array}$ & & $\begin{array}{l}\text { reference } \\
3.88\end{array}$ & $2.66-5.64$ & \\
\hline Histology & & & $<0.001$ & & & 0.001 \\
\hline $\begin{array}{l}\text { ADC } \\
\text { SQC } \\
\text { Others } \\
\text { SCC }\end{array}$ & $\begin{array}{l}8.5 \\
3.7 \\
1.5 \\
3.1\end{array}$ & $\begin{array}{l}5.7-11.3 \\
0.0-11.0 \\
0.0-4.2 \\
0.8-5.4\end{array}$ & & $\begin{array}{l}\text { reference } \\
2.07 \\
4.79 \\
2.25\end{array}$ & $\begin{array}{l}1.01-4.26 \\
1.86-12.36 \\
1.09-4.65\end{array}$ & $\begin{array}{l}0.048 \\
0.001 \\
0.029\end{array}$ \\
\hline M Stage & & & 0.002 & & & \\
\hline $\begin{array}{l}\text { M1a } \\
\text { M1b }\end{array}$ & $\begin{array}{l}10.9 \\
4.3\end{array}$ & $\begin{array}{l}6.9-14.9 \\
2.6-6.0\end{array}$ & & & & \\
\hline Treatment & & & 0.007 & & & \\
\hline $\begin{array}{l}\text { Supportive } \\
\text { Active }\end{array}$ & $\begin{array}{l}3.2 \\
10.9\end{array}$ & $\begin{array}{l}1.9-4.5 \\
8.1-13.7\end{array}$ & & & & \\
\hline Hemoglobin, $\mathrm{g} / \mathrm{dL}^{\mathrm{a}}$ & & & 0.004 & & & \\
\hline $\begin{array}{l}<12 \\
\geq 12\end{array}$ & $\begin{array}{l}3.3 \\
9.2\end{array}$ & $\begin{array}{l}0.7-5.9 \\
6.5-12.0\end{array}$ & & & & \\
\hline Albumin, $\mathrm{g} / \mathrm{dL}^{\mathrm{a}}$ & & & $<0.001$ & & & \\
\hline $\begin{array}{l}<3.1 \\
\geq 3.1\end{array}$ & $\begin{array}{l}2.6 \\
9.5\end{array}$ & $\begin{array}{l}1.1-4.0 \\
6.7-12.3\end{array}$ & & & & \\
\hline$L D H, I U / L^{a}$ & & & 0.119 & & & \\
\hline $\begin{array}{l}\leq 211 \\
>211\end{array}$ & $\begin{array}{l}10.6 \\
4.5\end{array}$ & $\begin{array}{l}8.1-13.1 \\
3.1-6.0\end{array}$ & & & & \\
\hline Calcium, mg/dL ${ }^{a}$ & & & $<0.001$ & & & \\
\hline $\begin{array}{l}\leq 10.8 \\
>10.8\end{array}$ & $\begin{array}{l}7.7 \\
1.0\end{array}$ & $5.1-10.2$ & & & & \\
\hline$s N L R$ & & & $<0.001$ & & & \\
\hline $\begin{array}{l}<3.85 \\
\geq 3.85\end{array}$ & $\begin{array}{l}12.6 \\
3.6\end{array}$ & $\begin{array}{l}9.7-15.6 \\
2.2-5.0\end{array}$ & & & & \\
\hline $\mathrm{mNLR}$ & & & 0.004 & & & \\
\hline $\begin{array}{l}<1.36 \\
\geq 1.36\end{array}$ & $\begin{array}{l}8.3 \\
2.4\end{array}$ & $\begin{array}{l}5.1-11.4 \\
0.5-4.3\end{array}$ & & & & \\
\hline smNLR score & & & $<0.001$ & & & 0.012 \\
\hline $\begin{array}{l}0 \\
1 \\
2\end{array}$ & $\begin{array}{l}12.6 \\
4.4 \\
1.6\end{array}$ & $\begin{array}{l}9.7-15.6 \\
2.7-6.0 \\
1.4-1.8\end{array}$ & & $\begin{array}{l}\text { reference } \\
1.37 \\
2.36\end{array}$ & $\begin{array}{l}0.95-1.98 \\
1.30-4.28\end{array}$ & $\begin{array}{l}0.090 \\
0.005\end{array}$ \\
\hline
\end{tabular}

Abbreviations: MST median survival time, mo month, Cl confidence interval, HR hazard ratio, ECOG PS Eastern Cooperative Oncology Group performance status, $A D C$ adenocarcinoma, $S Q C$ squamous cell carcinoma, SCC small cell carcinoma, $S N L R$ neutrophil-to-lymphocyte ratio of serum, $m N L R$ neutrophil-to-lymphocyte ratio of malignant pleural effusion, smNLR score score using neutrophil-to-lymphocyte ratios of serum and malignant pleural effusion Dichotomized by cutoff of normal value 

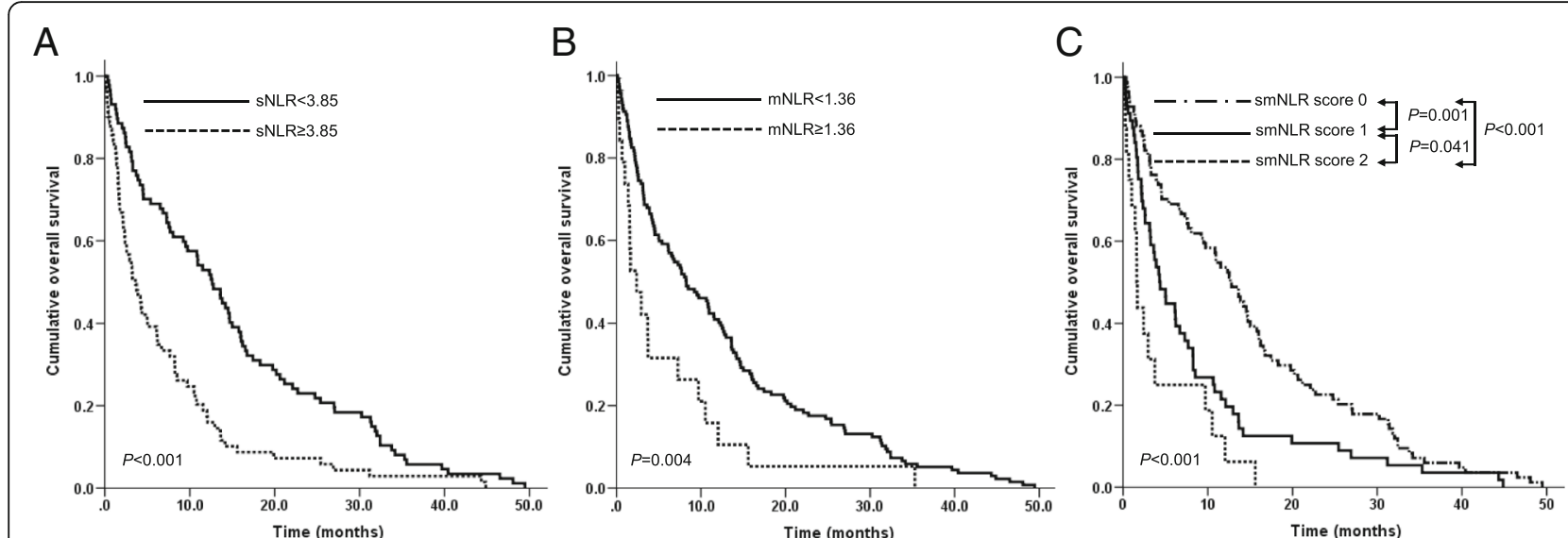

Fig. 1 Overall survival of the total study population according to (a) the neutrophil-to-lymphocyte ratio in serum (sNLR), (b) the neutrophil-tolymphocyte ratio in malignant pleural effusion (mNLR), and (c) the new score that encompasses the neutrophil-to-lymphocyte ratios in the serum and malignant pleural effusion (smNLR score)

the survival of patients with MPE, which may provide valuable additional prognostic information for doctors and patients. To the best of our knowledge, the present study is the first report on the prognostic impact of the smNLR score.

Inflammation has been reported to play an important role in different stages of tumorigenesis and is now considered a hallmark of cancer [20,21]. In recent years, many studies have investigated the most commonly used measures of the systemic inflammatory response, such as C-reactive protein, the Glasgow Prognostic Score, cytokines, and leucocytes, and their potential prognostic impact in cancer patients [22-26]. In addition, some systematic reviews have shown that the numbers of leucocyte subtypes, specifically the neutrophil and lymphocyte counts, are objective parameters with the ability to express the severity of the systemic inflammatory response in patients with cancer $[8,12,14]$. These studies have reported that an elevated SNLR has a consistent effect on adverse OS among patients with various solid tumors and the tumor stages. Recently, a study on the prediction of survival in patients with MPE showed that the sNLR is a significant prognostic factor in a multivariable analysis and that the LENT prognostic score (pleural fluid LDH, ECOG PS, the sNLR, and tumor type) has significantly higher accuracy than ECOG PS alone [5]. Therefore, the sNLR has enormous potential as a readily available and inexpensive biomarker. As shown by the present multivariate analysis, with the exception of the new smNLR score (Additional file 1: Table S1), the prognostic impact of the sNLR in lung cancer patients with MPE was consistent with the results of previous studies.

The mechanisms that are associated with high sNLR and poor outcome in cancer patients remain unclear. One potential mechanism that has been proposed involves the interactions between the tumor and host cells such as leucocytes due to an inflammatory response. As an inflammatory response, neutrophilia inhibits the immune system via the suppression of the cytolytic activity of immune cells such as lymphocytes and activated $\mathrm{T}$ cells. In addition, tumor-infiltrating lymphocytes have been reported to exert a positive effect on the survival of cancer patients. Taken together, the prognostic impact of the sNLR may be due to the association of a high sNLR with inflammation $[8,14,15,27]$. These potential mechanisms suggest that the mNLR could also have a potential prognostic impact in patients with MPE, but since the cause of MPE is still unclear, its impact may be ascribed to the hematogenous direct spread of tumor cells to the pleura $[2,3]$. In our study, we found that a higher mNLR was adversely associated with survival in lung cancer patients with MPE. In addition, the smNLR score was a more significant independent prognostic factor compared with the sNLR or mNLR alone. Another merit of the smNLR score is that it may be calculated based on tests that are routinely performed for patients with MPE in a variety of clinical settings.

One study reported that, compared with patients who received standard care, early palliative care of patients with advanced lung cancer was associated with improvement in the quality of life, less aggressive end-of-life care, and longer survival [6]. Therefore, in patients with advanced cancer, simpler, more useful, and more cost-effective clinical prognostic factors at presentation may help to not only individualize treatment strategies but also to minimize inconvenient and unnecessary aggressive treatment. Although further studies are required to apply our results to a clinical setting, the smNLR score may provide better information to clinicians and patients, which might enable them to select the most appropriate therapy for patients with MPE. 
This study has several limitations and strengths. First, this study is a single-center study with a relatively small sample size. The findings were also not validated in an independent series of patients, which limits our ability to generalize our findings. However, approximately $15 \%$ of lung cancer patients have been reported to present with pleural effusion; moreover, the diagnostic sensitivity of pleural fluid cytological and/or closed pleural biopsy analysis usually ranges from 40 to $87 \%$. Generally, the more invasive approach of thoracoscopy might be indicated when pleural cytology and/or biopsy are negative and MPE is still suspected [2,3]. All patients in our study were confirmed to have malignant cells in the pleural fluid or on pleural biopsy, and not all of our cases required the more invasive procedure. We believe that this inclusion criterion is causative of the size of the sample and the improvement in study quality. The present results using the mNLR may provide new implications for prognostic factors in patients with MPE, but validation is needed in another independent group to generalize our results. Second, the retrospective nature of this study is associated with limitations that pertain to selection, exclusion, and recall bias. However, although all items related to pleural fluid of all included patients who were diagnosed MPE were not available, the mNLR was available in all patients. Furthermore, general prognostic factors related to advanced lung cancer were considered in detail in this study [28]. Recently, molecular biomarkers, which were not considered in our study, have been demonstrated to be important prognostic factors in lung cancer patients. The test for epidermal growth factor receptor (EGFR) mutations has significant prognostic relevance in lung cancer patients, particularly in those with advanced adenocarcinoma [29, 30]. Unfortunately, the EGFR mutation test for MPE was not available at our institution during the time the present study was conducted. Finally, the NLR is a nonspecific variablethat may be influenced by concurrent conditions such as infections, inflammation, and medications. This limitation has been observed in most studies of the sNLR [8]. However, to maintain the quality of the present study, we included only patients in whom malignant cells were identified in the pleural fluid or on pleural biopsy, and none of the included cases had identifiable causes of infection, such as bacteria, tuberculosis, or viruses, in the blood, sputum, or MPE. We also determined the optimal cutoff values for the sNLR and the mNLR using maximally selected rank statistics $[10,11]$ to maintain the objectivity of our study.

\section{Conclusions}

In summary, high sNLR and mNLR values are associated with adverse OS, and the smNLR score is a more significant independent prognostic factor than the sNLR or the mNLR alone in lung cancer patients with MPE. To the best of our knowledge, this is the first study that has investigated the prognostic impact of the smNLR score in patients with MPE. This study suggests that the smNLR score may act as a simple, useful, and cost-effective prognostic factor in patients with MPE. Furthermore, these results may serve as the cornerstone of further research into the mNLR in the future. This information will benefit clinicians and patients in determining the most appropriate therapy for patients with MPE.

\section{Additional file}

Additional file 1: Table S1. Multivariate analyses of the factors that are predictive of overall survival in all patients apart from the new score, which use the neutrophil-to-lymphocyte ratios in the serum and malignant pleural effusion. (DOCX $16.8 \mathrm{~kb}$ )

\section{Abbreviations}

ADC: Aadenocarcinoma; Cl: Cconfidence interval; CRP: C-reactive protein; ECOG PS: Eastern Cooperative Oncology Group performance status; EGFR: Epidermal growth factor receptor; HR: Hazard ratio; LDH: Lactate dehydrogenase; mNLR: Neutrophil-to-lymphocyte ratio of malignant pleura effusion; mo: Month; MPE: Malignant pleural effusion; MST: Median survival time; OS: Overall survival; SCC: Small cell carcinoma; smNLR score: Score using neutrophil-to-lymphocyte ratios of serum and malignant pleural effusion; sNLR: Neutrophil-to-lymphocyte ratio of the serum; SQC: Squamous cell carcinoma

\section{Acknowledgements}

We would like to thank all the patients who are involved in our study and appreciate American Journal Expert team for English editing.

\section{Funding}

This study was supported by Inha University Hospital Research Grant. The funders had no role in the study design, data collection and analysis, decision to publish, or preparation of the manuscript.

\section{Availability of data and materials}

The dataset supporting the conclusions of the current study is included within the article and its additional file. The raw data generated and analysed during the current study are not publicly available since they contain potentially identifying information. However, some raw datasets of the current study are available from the corresponding author on reasonable request.

\section{Authors' contributions}

HSN and YSL designed the concept of the study. HSN, YM, JWC, JSR, SMK and HLL performed and participated in acquisition of clinical data. HSN, YSL, YM, JHL and JSK took part in data analysis and interpretation. HSN, YSL, JHL, and JSK drafted the manuscript. HSN, YM, JWC, JSR, SMK and HLL provided administrative support and revised the manuscript. All authors have read and approved the final version of the manuscript.

\section{Ethics approval and consent to participate}

The study protocol was approved by the Institutional Review Board of Inha University Hospital (INHAUH 2016-04-006). Informed consent was waived because of the retrospective nature of the study.

Consent for publication

Not applicable.

Competing interests

The authors declare that they have no competing interests. 


\section{Publisher's Note}

Springer Nature remains neutral with regard to jurisdictional claims in published maps and institutional affiliations.

\section{Author details}

'Department of Obstetrics and Gynecology, The Catholic University of Korea, Seoul 06591, South Korea. ${ }^{2}$ Division of Pulmonology, Department of Internal Medicine, Inha University Hospital, Inha University School of Medicine, 27, Inhang-ro, Jung-gu, Incheon 22332, South Korea. ${ }^{3}$ Department of Laboratory Medicine, Inha University Hospital, Inha University School of Medicine, Incheon 22332, South Korea.

Received: 28 March 2016 Accepted: 14 August 2017

\section{Published online: 22 August 2017}

\section{References}

1. Thomas JM, Musani Al. Malignant pleural effusions: a review. Clin Chest Med. 2013:34:459-71.

2. Light RW. Pleural diseases. 6th ed. Philadelphia: Lippincott Williams \& Wilkins; 2013.

3. Nam HS. Malignant pleural effusion: medical approaches for diagnosis and management. Tuberc Respir Dis (Seoul). 2014;76:211-7.

4. Goldstraw P, Crowley J, Chansky K, Giroux DJ, Groome PA, Rami-Porta R, et al. The IASLC lung cancer staging project: proposals for the revision of the TNM stage groupings in the forthcoming (seventh) edition of the TNM classification of malignant tumours. J Thorac Oncol. 2007:2:706-14.

5. Clive AO, Kahan BC, Hooper CE, Bhatnagar R, Morley AJ, Zahan-Evans N, et al. Predicting survival in malignant pleural effusion: development and validation of the LENT prognostic score. Thorax. 2014;69:1098-104.

6. Temel JS, Greer JA, Muzikansky A, Gallagher ER, Admane S, Jackson VA, et al. Early palliative care for patients with metastatic non-small-cell lung cancer. N Engl J Med. 2010;363:733-42

7. Ludwig JA, Weinstein JN. Biomarkers in cancer staging, prognosis and treatment selection. Nat Rev Cancer. 2005;5:845-56

8. Templeton AJ, McNamara MG, Seruga B, Vera-Badillo FE, Aneja P, Ocana A et al. Prognostic role of neutrophil-to-lymphocyte ratio in solid tumors: a systematic review and meta-analysis. J Natl Cancer Inst. 2014;106:dju124.

9. Bielsa S, Salud A, Martinez M, Esquerda A, Martin A, Rodriguez-Panadero F, et al. Prognostic significance of pleural fluid data in patients with malignant effusion. Eur J Intern Med. 2008;19:334-9.

10. Lausen B, Hothorn T, Bretz F, Schumacher M. Assessment of optimal selected prognostic factors. Biom J. 2004;46:364-74.

11. Hothorn T, Lausen B. On the exact distribution of maximally selected rank statistics. Comput Stat Data Anal. 2003:43:121-37.

12. Paramanathan A, Saxena A, Morris DL. A systematic review and metaanalysis on the impact of pre-operative neutrophil lymphocyte ratio on long term outcomes after curative intent resection of solid tumours. Surg Oncol. 2014:23:31-9.

13. Kang MH, Go SI, Song HN, Lee A, Kim SH, Kang JH, et al. The prognostic impact of the neutrophil-to-lymphocyte ratio in patients with small-cell lung cancer. Br J Cancer. 2014;111:452-60.

14. Guthrie GJ, Charles KA, Roxburgh CS, Horgan PG, McMillan DC, Clarke SJ. The systemic inflammation-based neutrophil-lymphocyte ratio: experience in patients with cancer. Crit Rev Oncol Hematol. 2013;88:218-30.

15. Chua W, Charles KA, Baracos VE, Clarke SJ. Neutrophil/lymphocyte ratio predicts chemotherapy outcomes in patients with advanced colorectal cancer. Br J Cancer. 2011:104:1288-95.

16. Kao SC, Pavlakis N, Harvie R, Vardy JL, Boyer MJ, van Zandwijk N, et al. High blood neutrophil-to-lymphocyte ratio is an indicator of poor prognosis in malignant mesothelioma patients undergoing systemic therapy. Clin Cancer Res. 2010;16:5805-13.

17. Cedres S, Torrejon D, Martinez A, Martinez P, Navarro A, Zamora E, et al. Neutrophil to lymphocyte ratio (NLR) as an indicator of poor prognosis in stage IV non-small cell lung cancer. Clin Transl Oncol. 2012;14:864-9.

18. Xiao W-K, Chen D, Li S-Q, Fu S-J, Peng B-G, Liang L-J. Prognostic significance of neutrophil-lymphocyte ratio in hepatocellular carcinoma: a meta-analysis. BMC Cancer. 2014;14:1

19. Szkandera J, Absenger G, Liegl-Atzwanger B, Pichler M, Stotz M, Samonigg $\mathrm{H}$, et al. Elevated preoperative neutrophil/lymphocyte ratio is associated with poor prognosis in soft-tissue sarcoma patients. Br J Cancer. 2013:108:1677-83.
20. Hanahan D, Weinberg RA. Hallmarks of cancer: the next generation. Cell. 2011;144:646-74.

21. Mantovani A, Allavena P, Sica A, Balkwill F. Cancer-related inflammation. Nature. 2008:454:436-44.

22. Siemes C, Visser LE, Coebergh JW, Splinter TA, Witteman JC, Uitterlinden AG, et al. C-reactive protein levels, variation in the C-reactive protein gene, and cancer risk: the Rotterdam study. J Clin Oncol. 2006;24:5216-22.

23. McMillan DC. The systemic inflammation-based Glasgow prognostic score: a decade of experience in patients with cancer. Cancer Treat Rev. 2013;39:534-40

24. Shafique K, Proctor MJ, McMillan DC, Leung H, Smith K, Sloan B, et al. The modified Glasgow prognostic score in prostate cancer: results from a retrospective clinical series of 744 patients. BMC Cancer. 2013;13:1.

25. Pine SR, Mechanic LE, Enewold L, Chaturvedi AK, Katki HA, Zheng YL, et al. Increased levels of circulating interleukin 6, interleukin 8, C-reactive protein, and risk of lung cancer. J Natl Cancer Inst. 2011;103:1112-22.

26. Teramukai S, Kitano T, Kishida Y, Kawahara M, Kubota K, Komuta K, et al. Pretreatment neutrophil count as an independent prognostic factor in advanced non-small-cell lung cancer: an analysis of Japan multinational trial organisation LCO0-03. Eur J Cancer. 2009;45:1950-8.

27. Gooden MJ, de Bock GH, Leffers N, Daemen T, Nijman HW. The prognostic influence of tumour-infiltrating lymphocytes in cancer: a systematic review with meta-analysis. Br J Cancer. 2011;105:93-103.

28. Brundage MD, Davies D, Mackillop WJ. Prognostic factors in non-small cell lung cancer: a decade of progress. Chest. 2002;122:1037-57.

29. Shamblin CJ, Tanner NT, Sanchez RS, Woolworth JA, Silvestri GA. EGFR mutations in malignant pleural effusions from lung cancer. Curr Respir Care Rep. 2013;2:79-87.

30. Lynch TJ, Bell DW, Sordella R, Gurubhagavatula S, Okimoto RA, Brannigan BW, et al. Activating mutations in the epidermal growth factor receptor underlying responsiveness of non-small-cell lung cancer to gefitinib. N Engl J Med. 2004;350:2129-39.

\section{Submit your next manuscript to BioMed Central and we will help you at every step:}

- We accept pre-submission inquiries

- Our selector tool helps you to find the most relevant journal

- We provide round the clock customer support

- Convenient online submission

- Thorough peer review

- Inclusion in PubMed and all major indexing services

- Maximum visibility for your research

Submit your manuscript at www.biomedcentral.com/submit
Biomed Central 